Revue d'histoire de l'Amérique française

DETHE D.HISTOIRE DE L'AMÉRIQUE FRANÇAISE

\title{
CORBO, Claude, avec la collaboration de Jean-Pierre COUTURE, Repenser l'école. Une anthologie des débats sur l'éducation au Québec de 1945 au rapport Parent (Montréal, Presses de l’Université de Montréal, 2000), 667 p.
}

\section{Claude Galarneau}

Volume 56, numéro 2, automne 2002

URI : https://id.erudit.org/iderudit/007334ar

DOI : https://doi.org/10.7202/007334ar

Aller au sommaire du numéro

Éditeur(s)

Institut d'histoire de l'Amérique française

ISSN

0035-2357 (imprimé)

1492-1383 (numérique)

Découvrir la revue

Citer ce compte rendu

Galarneau, C. (2002). Compte rendu de [CORBO, Claude, avec la collaboration de Jean-Pierre COUTURE, Repenser l'école. Une anthologie des débats sur

l'éducation au Québec de 1945 au rapport Parent (Montréal, Presses de

l'Université de Montréal, 2000), 667 p.] Revue d'histoire de l'Amérique française, 56(2), 279-279. https://doi.org/10.7202/007334ar d'utilisation que vous pouvez consulter en ligne. 
CORBO, Claude, avec la collaboration de Jean-Pierre COUTURE, Repenser l'école. Une anthologie des débats sur l'éducation au Québec de 1945 au rapport Parent (Montréal, Presses de I'Université de Montréal, 2000), 667 p.

Ceux qui ont vécu les années des commissions Massey, Tremblay et Parent seront heureux de prendre connaissance de ce livre et de se rappeler les débats de l'époque sur l'éducation au Québec. Ceux qui sont nés après 1945 pourront juger à quel point les réformes des années 1960 étaient nécessaires. Claude Corbo nous offre ainsi une anthologie de ce qui s'est écrit sur les problèmes de l'école depuis longtemps accumulés. Dans l'introduction, l'auteur rappelle les grandes dates du système scolaire et, de façon claire, il explique son objectif et pourquoi il ne remonte pas plus loin dans le temps. Les historiens de l'éducation savent que les débats ont commencé dès 1790 .

L'auteur et ses collaborateurs ont choisi les textes qui donnent une bonne idée du "grand débat scolaire québécois». Les textes montrent aussi bien les résistances aux changements que les projets novateurs qui permettent de mieux situer les rapports Parent et Rioux. Les critères du choix des textes ont été leur caractère public, c'est-à-dire publiés, la diversité des auteurs, individus, groupes, institutions, et celle des points de vue, idées et positions. Ouvrage d'une grande richesse en son genre, il apprendra aux uns et aux autres que les réformes des années 1960 ont été le fruit d'une longue réflexion et que, cela dit, la Révolution tranquille, comme toute révolution, n’a pas été une création soudaine. 